\title{
Prevalence of Chlamydia trachomatis in urine of male patients with ankylosing spondylitis is not increased
}

M van der Paardt, J C van Denderen, A J C van den Brule, S A Morré, I E van der Horst-Bruinsma, P D Bezemer, B A C Dijkmans

\begin{abstract}
Objective-To compare the prevalence of Chlamydia trachomatis infections in ankylosing spondylitis (AS) patients with controls, using DNA amplification assays in urine specimens.

Methods-The prevalence of $C$ trachomatis infections was assessed in 32 male AS patients and 120 age and sex matched controls. Urine specimens were tested by ligase chain reaction and polymerase chain reaction. In addition, blood samples of AS patients were tested on serum antibodies to $C$ trachomatis (IgA and IgG) by a specific peptide based solid phase enzyme immunoassay. A questionnaire was used to assess the differences in sexual behaviour and ethnic origin between the two groups. AS patients were also asked about disease characteristics.

Results-No significant differences were found between cases and controls in the prevalence of $C$ trachomatis infections. No associations were found between $C$ trachomatis antibodies and disease characteristics, except for acute anterior uveitis (AAU). Four of eight $(50 \%)$ AS men positive for IgG had a history of AAU in comparison with three of $24(12.5 \%)$ IgG negative men $(O R=7.0 ; 95 \%$ confidence intervals: $1.1,44.1$ ).
\end{abstract}

Conclusion-The prevalence of Chlamydia trachomatis infections, as detected by commercially available DNA amplification assays in urine specimens, in AS patients is not higher compared with male controls of the same age. However, there seems to be an association between specific antibodies to $C$ trachomatis and AAU.

(Ann Rheum Dis 2000;59:300-302)

Ankylosing spondylitis (AS) and reactive arthritis (ReA) are closely related disorders. Whereas a gastrointestinal or an urogenital infection is almost by definition considered to provoke $\mathrm{ReA}$, the causative role of an infectious agent in AS is still a matter of debate.

The role of Chlamydia trachomatis in ReA has been established, while its role in the pathogenesis of AS remains unclear. German studies report a prevalence of $15 \%-20 \%$ Chlamydia trachomatis infections, as detected in urethra swabs, in male AS patients ${ }^{1-3}$; however, information from controls and confirmation from other laboratories is lacking.
Recently, commercially available DNA amplification assays - ligase chain reaction (LCR) and polymerase chain reaction (PCR) - have been introduced for the detection of Chlamydia trachomatis. These assays have higher sensitivities $(90 \%-95 \%)$ and specificities (>99\%) for the detection of $C$ trachomatis in urine specimens compared with the conventionally used assays of urethra swabs, culture $(65 \%-80 \%$ and $100 \%$, respectively) and enzyme immunoassay $\left(60 \%-85 \%\right.$ and $99 \%$, respectively). ${ }^{45}$ This development makes the LCR and PCR a valuable, reliable and painless tool to investigate $C$ trachomatis in groups of interest. ${ }^{6-8}$

The objective of this study was to compare the prevalence of $C$ trachomatis infections in AS patients with controls, using commercially available DNA amplification assays in urine specimens.

\section{Methods}

Cases were male AS patients, according to the Modified New York Criteria, ${ }^{9}$ visiting the outpatient clinics of the Jan van Breemen Institute and the University Hospital Vrije Universiteit. Inclusion criteria were: age between 20-40 years (most sexually active period), disease duration-as defined by the diagnosis of a rheumatologist - of at most 10 years (to limit the possibility of an infection after onset of AS) and being a resident of Amsterdam (for comparison with the controls).

Controls were men in the same age group from the general population of Amsterdam. The controls were obtained by a random sample from the cohort of a current study dealing with the systematic screening for asymptomatic urogenital infections with $C$ trachomatis in men and women in general practice. ${ }^{10}$ This survey comprised a random sample of men and women, aged 15-40 years, selected in such a way that the sample reflected the population of Amsterdam.

This study was approved by the ethical committees of the participating hospitals. After informed consent, each participant was sent a questionnaire on demographic characteristics and sexual behaviour, including the use of condoms. Moreover AS patients were also asked about disease characteristics, with emphasis on arthritis, achillotendinitis, cardiac involvement and uveitis. All participants were asked to collect in a container $20 \mathrm{ml}$ first stream and first voided urine. The urine specimens were tested by DNA amplification assays, LCR (LCx, Abbott Laboratories, Chicago, IL, USA) and
Accepted for publication 16 December 1999 
Table 1 Prevalence of an infection with Chlamydia trachomatis in patients with ankylosing spondylitis and controls *

\begin{tabular}{lll}
\hline & \multicolumn{1}{l}{ Group } & \\
\cline { 2 - 3 } & \multicolumn{1}{c}{ Patients $(n=32)$} & \multicolumn{1}{c}{ Controls $(n=120)$} \\
\hline Infection with $C$ trachomatis & 1 & 3 \\
Prevalence of $C$ trachomatis $(95 \% \mathrm{CI})$ & $3.1 \%(0.1,16.2 \%)$ & $2.5 \%(0.5,7.2 \%)$ \\
Prevalence of $C$ trachomatis (direct standardisation by age) & $2.5 \%$ & $2.5 \%$ \\
\hline${ }^{\star} C$ trachomatis detected by LCx and Amplicor in urine specimens; no differences in positivity were found in samples tested. $\dagger$ Fish- \\
er's exact test.
\end{tabular}

PCR (Amplicor, Roche Diagnostic Systems, Basel, Switzerland). In addition, blood samples were obtained from AS patients to assess serum antibodies to $C$ trachomatis (IgA and IgG) by a specific peptide based solid phase enzyme immunoassay (Labsystems, Helsinki, Finland).

The prevalences of the $C$ trachomatis infections were compared between cases and controls. As the prevalence of $C$ trachomatis infections decreases gradually with age, ${ }^{10}$ the prevalences were also calculated (directly) standardised for age, with age divided into four quinquennial categories. The control group was used as standard. In addition, the possible confounders sexual behaviour and ethnic origin were compared between cases and controls. To assess the possible differences in proportions we used the $\chi^{2}$ test or, if needed, Fisher's exact test. Exact confidence intervals for the prevalences were computed, based on the binomial distribution. After logarithmic transformation, the two sample $t$ test was used to evaluate the differences in the total number of sexual relations between patients and controls.

\section{Results}

Of 450 AS patients 68 fulfilled the inclusion criteria. Of these patients 20 had moved and were thereby lost to follow up. From the 48 remaining patients $32(66.7 \%)$ responded. The 36 eligible AS patients who could not be included did not differ from the 32 responders with regard to ethnic origin, but had a higher age and a longer disease duration of AS.

In the group of 32 responders $28(82 \%)$ patients were HLA-B27 positive. The mean duration of the disease was four years (range: some months to 10 years; SD 2.6), the mean age was 32 years (range: 21 to 40 years; SD 4.5).

The population survey consisted of 1336 (36\%) men. For reasons of statistical efficiency, we limited our random sample from this survey to 120 controls, in the same age range as the patients.

No significant difference was found in the prevalence of $C$ trachomatis in urine specimens between patients and controls, using the commercially available DNA assays; the unstandardised and standardised prevalences were identical (table 1). Between LCR and PCR no differences were found in positivity in the samples tested. No significant difference was found between cases and controls with regard to the age distribution, as divided into four quinquennial categories. Comparing the possible confounders no significant differences were found between cases and controls with regard to sexual disposition, marital status, new sexual relationships two months before our study, the total number of different sexual relationships six months before our study, the total number of different sexual relationships in the past and the use of condoms. With regard to the ethnic origin the patient group was significantly different $(p<0.01)$ from the control group in the number of Turkish men, six $(18.8 \%)$ and four $(3.3 \%)$, respectively.

In the group of AS patients seven (21.9\%), eight $(25.0 \%)$ and five $(15.6 \%)$ were positive for $C$ trachomatis $\operatorname{IgA}, \operatorname{IgG}$ and $\operatorname{IgA} / \operatorname{IgG}$, respectively. Preliminary analysis showed no associations between $C$ trachomatis antibodies and disease characteristics, except for AAU. Four of eight $(50.0 \%)$ and three of five $(60 \%)$ AS men positive for IgG and IgA/IgG, respectively, had a history of AAU in comparison with three of $24(12.5 \%)$ IgG negative men (OR = 7.0 ; $95 \%$ CI: $1.1,44.1)$ and four of $27(14.8 \%)$ $\mathrm{IgA} / \mathrm{IgG}$ negative men $(\mathrm{OR}=8.6$; 95\% CI: 1.1 , 69.1), respectively.

\section{Discussion}

This study did not show a significant difference between 32 AS patients and 120 controls in the prevalence of $C$ trachomatis infections, as detected in urine specimens by DNA amplification methods. Based on the data acquired by a questionnaire we concluded that cases and controls were comparable in sexual behaviour, so differences in sexual behaviour did not bias our study. With regard to ethnic origin the percentage of Turkish men was significantly higher among cases than controls. According to data from the Municipal Health Service in Amsterdam, the Turkish inhabitants and the rest of the population are comparable with regard to the prevalence of $C$ trachomatis urogenital infections. ${ }^{11}{ }^{12}$ Therefore it was not likely that this difference biased the outcome of our study either.

Although no increased risk was observed in case of $C$ trachomatis infection a causative relation cannot be excluded, but the role of persistent infections with $C$ trachomatis becomes less probable.

As the LCR and PCR have higher sensitivities and specifities for the detection of $C$ trachomatis in urine specimens compared with the conventionally used assays of urethra swabs, ${ }^{45}$ the only explanation for the discrepancy between the results of this study as assessed with LCR and PCR and those of the earlier mentioned German study group ${ }^{1-3}$ is that the latter also examined prostatic fluid, which might increase the chance of detection. Considering this discrepancy further research in the possible causative role of $C$ trachomatis in the pathogensis of AS remains necessary. 
To our knowledge to date there is no publication on the prevalences of specific $C$ trachomatis antibodies among men in the general population to compare with the prevalences of the antibodies among AS patients, as found in this study. The association of specific antibodies to $C$ trachomatis and AAU needs further research into the possible causative role for $C$ trachomatis in the pathogenesis of AAU.

The main conclusion from this study is that the prevalence of $C$ trachomatis infections, as detected by the currently available commercially DNA amplification assays, in urine specimens, in AS patients is not higher compared with male controls in the same age group.

The authors wish to thank Irene van Valkengoed, Joan Boeke, Jacques van Eijk and Chris Meijer for supplying the control group.

1 Weidner W, Schiefer HG, Schmidt KL. Urogenitale Infectionen bei seronegativer "reactiver" Arthrtis und
ankylosierender Spondylitis. Akt Rheumatol 1982;7:82-5. 2 Schiefer HG, Weidner W, Krauss H, Gerhardt U, Schmidt Schiefer HG, Weidner W, Krauss H, Gerhardt U, Schmidt
RL. Rheumafactor-negative Arthritis und Infectionen des RL. Rheumafactor-negative Arthritis und Infectionen des
männlichen Urogenitaltraktes. Zentrabl Bakteriol Hyg I männlichen Urogenitaltraktes.

3 Lange U, Berliner M, Weidner W, Schiefer HG, Schmidt RL, Federlin K. Ankylosierende Spondylitis und Urogenital infection: Urologische Infectionsdiagnostik und Korrelation mit rheumatologischen Befunden. Z Rheumatol 1996;55:249-55.
4 Schepetiuk S, Kok T, Martin L, Waddell R, Higgins G. Detection of Chlamydia trachomatis in urine samples by nucleic acid tests: comparison with culture and enzyme immunoassays of genital swab specimen. J Clin Microbiol 1997;35:3355-7.

5 Schachter J. DFA, EIA, PCR, LCR and other technologies; what tests should be used for diagnosis of Chlamydia infections? Immunol Invest. 1997;26:157-61.

6 Lee HH, Chernesky MA, Schachter J, Burczak JD, Andrews WW, Muldoon S, et al. Diagnosis of Chlamydia trachomatis genitourinary infection in women by ligase chain reaction assay of urine. Lancet 1995;345:213-16.

7 Chernesky MA, Chong S, Jang D, Luinstra K, Sellors J, Mahony JB. Ability of commercial ligase chain reaction and PCR assays to diagnose Chlamydia trachomatis infections PCR assays to diagnose Chlamydia trachomatis infections in men by testin

8 Morré SA, van Valkengoed IG, de Jong A, Boeke AJ, van Eijk JT, Meijer CJ, et al. Mailed home obtained urine specimens: a reliable screening approach for detecting asymptomatic Chlamydia trachomatis infections. J Clin Microbiol 1999;37:976-80.

9 Van der Linden S, Valkenburg HA, Cats A. Evaluation of diagnostic criteria for ankylosing spondylitis: a proposal for modification of the New York criteria. Arthritis Rheum 1984;27:361-8.

10 Van Valkengoed IG, Boeke AJ, van den Brule AJ, Morrê SA, Dekker JH, Meijer CJ. Systematic screening for asymptomatic Chlamydia trachomatis infections by home obtained mailed urine samples in men and women in general mactice. (In Dutch). Ned Tijdschr Geneeskd 199;143: 672-6.

11 Van den Hoek JA, Mulder-Folkerts DK, Coutinho RA, Dukers NH, Buimer M, Doornum GJ. Opportunistic screening for genital infections with Chlamydia trachomatis among the sexually active population of Amsterdam. I. Over $90 \%$ participation and almost $5 \%$ prevalence. (In Dutch). Ned Tijdschr Geneeskd 1999;143:668-72.

2 van de Laar MJ, Lan J, van Duynhoven YT, Fennema JS, Ossewaarde $\mathrm{JM}$, van den Brule AJ, et al. Differences in clinical manifestations of genital chlamydial infections related to serovars. Genitourin Med 1996;72:261-5. 